\title{
Estimating the Value of Electricity Storage in Chile Through Planning Models with Stylized Operation: How Wrong Can It Be?
}

\author{
Eduardo Pereira-Bonvallet ${ }^{1} \cdot$ Rodrigo Moreno $^{2,3,4}$ (i) $\cdot$ Francisco D. Muñoz ${ }^{5}$
}

Accepted: 28 August 2020 / Published online: 20 October 2020

(C) The Author(s) 2020

\begin{abstract}
Purpose of Review In light of the increased renewables penetration in power systems around the world, policy-makers, regulators, planners, and investors are significantly interested in determining the participation of energy storage in prospective scenarios of future generation capacity. In this context, this paper demonstrates the numerical errors associated with electricity planning models with stylized operation, which are of common use nowadays. We particularly focus on errors when quantifying the benefits of pumped hydro storage (PHS).

Recent Findings The latest research identifies important distortions in the results of infrastructure expansion planning problems originated due to a stylized representation of power system operation. These distortions have been particularly emphasized in power systems with increased penetration of renewables generation that necessitate higher levels of flexibility to deal with variability and uncertainty.

Summary Apart from providing a comprehensive literature review in this subject, we provide additional and novel quantitative evidence focusing on the impacts of additional PHS capacity in power systems. Thus, we compare the outputs from two models: (i) a planning model with a stylized operation that ignores operational details in long-term investment analysis, approximating operational costs through a discretized version of the load curve (i.e., time slice representation), and (ii) a state-of-the-art, advanced planning model that recognizes operational details, including hourly resolution and technical limitations of generation plants (through the so-called unit commitment variables and constraints). Both models co-optimize generation and transmission capacity by minimizing total system investment and operational costs. Through several case studies on the Chilean power network by 2025, it is demonstrated that the benefits in terms of cost savings from PHS are significantly underestimated by the stylized model that ignores operational details. In effect, the stylized model undermines both peaking generation capacity and network capacity deferred by storage as well as the operational cost savings due to reserves and flexibility provisions from PHS. Moreover, it is shown that while $\mathrm{CO}_{2}$ emissions are reduced in the advanced model (as expected), these are increased in the stylized model, which corresponds to a remarkable misleading result. Finally, revenue projections of PHS by using primal and dual information are calculated from both optimization approaches, demonstrating that the stylized approach is biased and erroneously diminishes the PHS revenue in the case of a bulk, transmission-connected PHS in Chile. These conclusions are of particular interest for policy-makers, regulators, planners, and investors in Chile who seek to identify both PHS projects that are socially optimal (minimizing overall system costs) and privately profitable (whose revenues exceed costs).
\end{abstract}

Keywords Energy storage $\cdot$ Pump hydro storage $\cdot$ Long-term planning with unit commitment constraints $\cdot$ Flexibility · Power system economics

This article is part of the Topical Collection on Regional Renewable Energy - Chile

Rodrigo Moreno

rmorenovieyra@ing.uchile.cl

Extended author information available on the last page of the article.

\section{Introduction}

Renewables generation plays a key role in the transition towards decarbonization. In fact, this has been widely acknowledged by several governments around the world, which are already committed to promote increased levels of renewables in their energy system, aiming to decarbonize 
electricity and also electrify other energy vectors. This transition is facilitated by the significant decrease in the investment costs of wind and solar photovoltaics (PV) power plants, making these technologies more and more competitive, representing an attractive alternative to conventional generation technologies such as coal and natural gas-fired units [1]. Following this trend, during 2018 and for the fourth year in a row, new capacity additions in renewables surpass those of all conventional generation technologies combined [2].

A paramount challenge for the large-scale integration of renewables is the need for flexibility to deal with the variability and unpredictability of wind and solar power generation. Among the different flexibility sources, energy storage (ES) is seen as one of the key technologies that will enable the large-scale integration of variable renewable energy. Indeed, besides the classical service of temporal energy arbitrage, ES can provide an array of ancillary services and drive investment deferrals in both generation and transmission, while accommodating increased amounts of renewables [3, 4]. Hence, ES has gained considerable attention from policy-makers and researchers globally. Economic and technical analyses regarding ES impacts and benefits, optimal sizing, market design and regulation, business models, among other themes, have been widely reported in the literature as discussed next.

Regarding the ES value streams, in [5], the authors identify and calculate a significantly higher value of storage when including multiple services that ES is able to provide. In [6], the authors show the importance of a multi-year multi-service approach for the optimal sizing of storage, including primary and secondary reserves. Also, the importance of co-planning transmission and generation expansions jointly with ES capacity shows how larger savings can be reached due to deferral of network and generation infrastructure [7].

Contribution of storage to system capacity adequacy has been reported under several methodologies. For example, in [8], the authors present a dynamic programming-based method to estimate the capacity value of an energy storage system. Their findings indicate that the capacity value of ES could range between 40 and $100 \%$ of name-plate discharge capacity, depending on storage duration. New frameworks for capacity credit determination are proposed in [9] in order to account for specific characteristics of ES.

In addition to the previous applications, in $[10,11]$ the authors studied how ES can provide a hedge against uncertainty in future system developments. ES is a flexible asset with potentially shorter deployment times than reinforcements in the grid; therefore, it can grant planners the ability to delay decisions and react to unfolding uncertainty until reinforcements are fully justified.

On top of the applications discussed, ES can aid in the fulfillment of carbon reduction targets more efficiently due to several reasons. ES operation leads to an improved operational efficiency of conventional plants, by reducing startup/shutdown cycles, ramps, and partial load operation [7]. In the same way, ES can minimize the curtailment of clean renewable energy by storing it for later use [12]. Moreover, mix of ES with renewable energy can replace base load capacity, such as coal-based units, aiding in the secure decommissioning of these plants [3]. Remarkably, in [13], the authors have obtained a larger integration of renewables reducing participation of nuclear energy, reaching the same carbon emissions limit, but at a lower cost.

Many of the questions concerning ES in the literature have been addressed by using mathematical tools and models with different levels of operational detail representation. Therefore, it is expected that the main conclusions are conditional to the modelling scope of these tools. Proper modelling of variability and operational constraints, as well as multiple service provision, are key to valuing operationally flexible solutions correctly. However, computational burden arises quickly as more details are introduced; therefore, representation of operational detail in planning has been very limited. Simplifications are introduced through representative periods — days or weeks per year [7][13]—-technology clustering of generating units [14], neglecting short-term operating constraints, or other requirements such as ancillary services or reliability constraints [15]. In this vein, planning authorities, regulatory offices, and policy-makers have faced the need to include a number of simplifications in energy planning studies. For example:

- In the USA, there are various energy planning models commonly used by relevant agencies and institutions that ignore hourly variability and unit commitment constraints, among them [16]: the Integrated Planning Model (IPM) used by the U.S. Environmental Protection Agency; the National Energy Modeling System (NEMS) used by the U.S. Energy Information Administration; the Regional Energy Deployment System (ReEDS), developed by the National Renewable Energy Laboratory (NREL); and the United States Regional Economy, Greenhouse Gas, and Energy (US-REGEN) model, developed by The Electric Power Research Institute (EPRI).

- The TIMES model, internationally used for planning purposes, also ignores detailed operation in terms of 
hourly resolution and the discrete variables needed to model inflexibility of conventional generation $[17,18]$.

- In Chile, the Power Electricity Timetable (PET) model used by the Energy Ministry to run its long-term energy planning exercise (PELP, due to its acronym in Spanish) every 5 years considers only 8 annual time slices with no consideration of unit commitment constraints [19]. The OSE2000 model, used by the National Energy Commission of Chile to identify optimal transmission network reinforcements and plan new storage capacity, features the same simplifications [20].

Recently, there is a body of work arising that has started to analyze the impacts of using a stylized operation representation within long-term energy planning models. These studies have analyzed the importance of temporal resolution [21-23] and operational flexibility (i.e., full set of unit commitment constraints or a subset of them) $[7,14,24,25]$, concluding that modeling detail is paramount to correctly assess the value of new technologies in future energy systems. Also, reference [26] studied the importance of these features combined within a stochastic optimization framework, determining the optimal generation mix, including energy storage, in a greenfield fashion and in a single busbar representation of the Chilean power system.

In this paper, we estimate the value of incremental energy storage capacity, particularly pumped hydro storage (PHS), in the Chilean electricity market by using two mathematical models with different levels of simplification. The key distinction between these two models is the treatment of operational details within the planning process. Hence, a long-term planning model with stylized operation, commonly used by planners and regulators, is compared with a more advanced model, where system operation is modeled with high resolution within the planning process, accounting for hourly unit commitment constraints and reserves. Under both modeling frameworks, contributions of incremental PHS capacity to cost savings in operation and investments are assessed in a realistic case study of the Chilean power system, with high levels of wind and solar power generation capacity in 2025. Apart from cost savings, we also determine, by using the two modeling approaches, the benefits of storage in terms of reductions in $\mathrm{CO}_{2}$ emissions and renewables curtailments, as well as the revenue streams for storage plant owners.

This paper is structured as follows. In Section 5, the two modelling approaches are explained in detail, and the case studies are presented. In Section 5, the numerical results are presented and analyzed. Finally, Section 5 presents the main conclusions drawn from this study.

\section{Methodology}

\section{Overview}

This study estimates the value of incremental energy storage capacity in the Chilean electricity market by using two mathematical models with different levels of simplification. In particular, we assess the impact of a PHS plant of 300 MW and $21.6 \mathrm{GWh}$ (i.e., $72 \mathrm{~h}$ of storage duration ${ }^{1}$ ) located north of the country. We select this location as, in our studies, we analyze future scenarios with large penetration of solar power generation in the northern area. Importantly, this area includes the Atacama desert, where solar irradiance is one of the highest in the world, with maximum values circa $1200 \mathrm{~W} / \mathrm{m}^{2}$ (in Global Horizontal Irradiance) [27]. Also, this location has been previously identified by the Chilean regulator, the National Energy Commission, to install energy storage capacity and thus support effective integration of solar power generation [28].

For estimating the value of PHS capacity, we determine optimal future system operation and investments for given scenarios of penetration of renewable generation with and without the 300-MW PHS plant, focusing on how the incremental energy storage capacity impacts system operation, network expansions, the need for peaking plant capacity, $\mathrm{CO}_{2}$ emissions, and renewables curtailments. We undertake this value assessment by using two optimization models, one with more simplifications than the other. Hence, the more simplified model (called the stylized model in this paper) seeks to resemble the levels of simplifications commonly used by regulators to run a cost-benefit analysis. The more advanced, detailed model, on the other hand, captures state-of-the-art features, particularly in terms of including a high resolution of system operation within the planning problem.

The advanced model (AM) optimizes system operation along with the expansions of the transmission network and peaking plant capacity. To do so, it minimizes operational and investment costs within a single year (i.e., static model), recognizing, as input parameters, existing network capacity and future generation capacity expansions of renewables and other generation technologies, beside peaking plant capacities that are optimized. The key feature of the $\mathrm{AM}$ is the high resolution of system operation, including hourly dispatch, unit commitment constraints (i.e., ramp rate limits, minimum stable generation levels, minimum upand downtimes, and reserves), and startup and shutdown

\footnotetext{
${ }^{1}$ Seventy-two hours of storage duration means that the plant can be discharged at full power output during $72 \mathrm{~h}$ in a continuous, uninterrupted fashion, provided that the upper reservoir is full at the beginning of the discharge period.
} 
costs. The stylized model (SM), instead, seeks to optimize the same operational and investment decisions, but with a lower resolution of system operation, ignoring unit commitment constraints, startup and shutdown costs, and clustering consecutive hours in time slices. As mentioned earlier, the SM seeks to resemble common simplifying assumptions applied by regulators and planners in long-term energy planning studies. Hence, we aim to find the size of the numerical errors associated with these simplifying assumptions.

\section{Model Description}

\section{The Advanced Model}

The advanced model corresponds, fundamentally, to a system planning mathematical program that optimizes both new system investments (in generation and transmission) and the corresponding system operation over a year. Examples of models that can optimize generation and transmission, along with system operation, can be found in $[29,30]$. In this paper, we use these planning tools by eliminating the feature of generation expansion, except for peaking plants, and increasing the resolution of the system operation representation. By planning peaking plant capacity only, we aim to estimate the value of energy storage capacity for given future scenarios of generation expansions, while, at the same time, assessing the ability of the energy storage plant to contribute to capacity adequacy by displacing "firm" generation capacity. Hence, the advanced model optimizes generation dispatches, including that of the given PHS plant, along with transmission network expansions and capacity of peaking plants. The general structure of this problem is shown in Table 1.
Table 1 Structure of the advanced long-term planning model with high operational resolution used to assess the value of PHS




One of the key features of the AM is the high resolution of system operation, including full representation of the unit commitment constraints (explained in detail in [31, 32]), and the startup and shutdown costs in an hourly fashion. As explained in [11, 33, 34], one of the main disadvantages of incorporating such details in planning models is that these become intractable, originating the need for advanced algorithms to solve the planning problem. Indeed, the planning problem becomes a very large mixed integer linear program (MILP). In this vein, we use similar approaches as in [33] to solve our problem.

\section{The Stylized Model}

The stylized model seeks to optimize the same problem as the AM, but with a set of simplifying assumptions to make the problem tractable. These simplifying assumptions are selected in order to resemble current practices in regulatory offices over the world, including Chile. These simplifications are:

- Time slices rather than hourly operation: In the stylized model, hourly profiles of nodal demands and renewable generation are clustered so as to reduce computational burden. In our study, we use 16 time slices or "blocks" per month and, consequently, 192 per year to capture different levels of demands and outputs of renewable generation.

- Absence of unit commitment constraints and associated costs: The stylized model does not consider reserves, ramp rate limits, minimum up- and downtimes, and startup and shutdown costs of conventional units. The main advantage of doing so is that system operation becomes fully linear (i.e., linear program) without the need to incorporate integer or binary variables for system operation as in the advanced model. In terms of algorithms, this problem can be usually solved in its monolithic form by using commercial software. Very large instances of the stylized planning problem can be solved by applying a classical Benders decomposition, with an upper level optimizing investment decisions and a lower level (fully linear and so convex) optimizing operational decisions as explained in [35, 36].

Expectedly, these simplifying assumptions will affect the results. In this vein, we aim to study the size of the numerical errors associated with these simplifications and their implications on long-term energy planning studies with energy storage, particularly for PHS plants.

\section{Case Studies}

\section{Input Data}

We model the Chilean electricity market in 2025, focusing on the value of a PHS plant of $300 \mathrm{MW}$ and $21.6 \mathrm{GWh}$ (i.e., $72 \mathrm{~h}$ of storage duration) located in the north of the country. We use two future scenarios of generation expansion based on the latest projections made by the Chilean Energy Ministry [19]. These two scenarios are shown in Table 2. This table also shows that the current generation mix is dominated by hydro (28\%), coal (20\%), and LNG (18\%). However, this is rapidly changing as new projects based on renewable technologies such as wind and solar power are dramatically increasing. Furthermore, we expect that the combined share of wind and solar generation increases from the current $19.8 \%$ to, at least, $32 \%$ by 2025 , which is higher than the share of any other technology. Note that Table 2 is a summary of the 496 units modeled at a national level.

We use a simplified representation of the Chilean transmission network with 44 nodes. Figure 1 shows the location of the 15 main nodes that represent the national
Table 2 Installed capacity connected to the transmission network by technology and its share: current and 2025 scenarios (capacity values in MW).

\begin{tabular}{llll}
\hline Technology & Current 2019 & 2025 scenario 1 & 2025 scenario 2 \\
\hline Hydro & $6709(28 \%)$ & $7347(25 \%)$ & $7347(23 \%)$ \\
Coal & $4797(20 \%)$ & $4797(16 \%)$ & $4797(15 \%)$ \\
LNG & $4347(18 \%)$ & $4347(15 \%)$ & $4347(14 \%)$ \\
Diesel & $2944(12 \%)$ & $2944(10 \%)$ & $2944(9 \%)$ \\
Solar & $2691(11 \%)$ & $4577(16 \%)$ & $6733(22 \%)$ \\
Wind & $2136(8.8 \%)$ & $4588(16 \%)$ & $4588(15 \%)$ \\
Biomass & $471(2 \%)$ & $471(2 \%)$ & $471(2 \%)$ \\
Geothermal & $40(0.1 \%)$ & $40(0.1 \%)$ & $40(0.1 \%)$ \\
Cogeneration & $18(0.1 \%)$ & $18(0.1 \%)$ & $18(0.1 \%)$ \\
Total & & & 31,287 \\
\hline
\end{tabular}




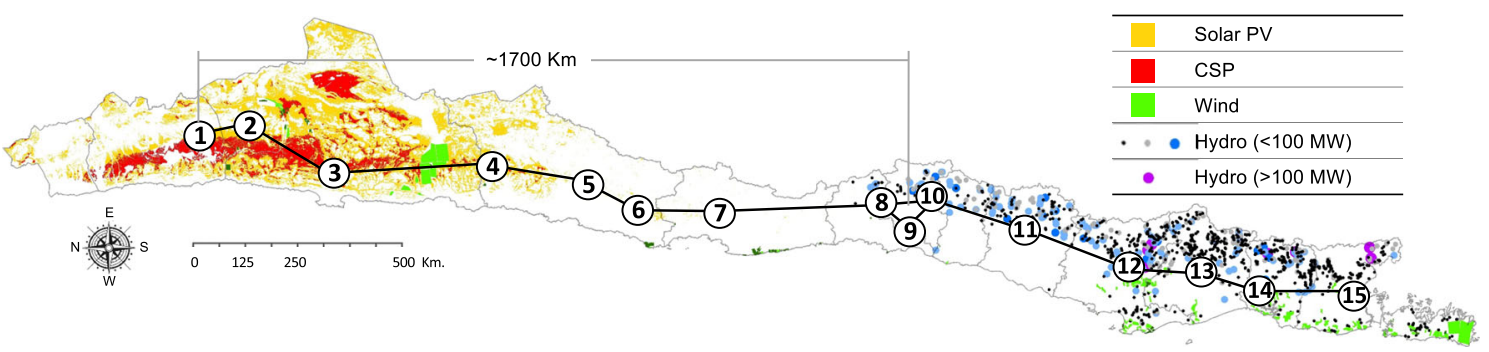

Fig. 1 The Chilean power system and its renewable energy resources [37]. Colors are used to show the renewables potential in areas with PV, wind, concentrated solar power (CSP), and hydro that present a load factor higher than 30,30, 50, and 50\%, respectively

grid $^{2}$, along with the location of potential capacity of solar, wind, and hydro generation. As shown in Fig. 1, there is a significant potential for solar power generation in the north of Chile (nodes 1-3), while the demand center (i.e., Santiago) is located far away in nodes 8-10. This suggests that significant capacity of a new transmission network might be needed and that a PHS plant located in the north (in node 1) can create important benefits in terms of accommodating increased amounts of solar power generation in a congested network.

The technical and cost information necessary to model the economic dispatch of the Chilean system are obtained from official and public documentation by the system operator [38] and the energy ministry [19]. This includes technical parameters of power plants (such as minimum and maximum capacities, ramp rate limits, minimum up- and downtimes), cost parameters (fuel costs, startup and shutdown costs), system reserves requirements, sizes of hydro reservoirs, the hydro network necessary to appropriately model the hydro connections related to hydro plants located in the same basin, and the profiles of nodal demands, wind, solar, and hydro inflows. As the dominating generation technology in Chile corresponds to hydro, a great deal of effort is put into appropriately modeling basins. As an example, Fig. 2 shows the hydro connections among various series power plants in the Biobío river basin. Note that the datasets involved here are extremely large as we model every individual power unit. Hence, rather than specifying parameters of individual generators, we chose to show some of the main system parameters in Table 3. In addition, Fig. 3 shows the relevant daily profiles in terms of averages and deviations in a year. For specific data, we address the reader to the abovementioned references.

Importantly, although we assess the impacts of incremental PHS capacity on $\mathrm{CO}_{2}$ emissions, we do not penalize emissions by using a carbon tax, carbon price, or other similar policies. In other words, we use a carbon price equal to

\footnotetext{
${ }^{2}$ The other 29 nodes represent the so-called zonal transmission network or subtransmission.
}

$0 \$ / \mathrm{tCO}_{2}$ in our assessments. We do so because the existing carbon tax policy applied in Chile, with a tax level equal to $5 \$ / \mathrm{tCO}_{2}$, cannot be used to modify real system operation. This will be explained in more detail in the following section.

Finally, the PHS unit studied features a total power capacity of $300 \mathrm{MW}$, a roundtrip efficiency of $75 \%$ and $72 \mathrm{~h}$ of energy storage capacity with three independent reversible turbines. Although the power output can be fully controlled when the PHS discharges in a continuous fashion, it only presents three discrete output levels (equal to 100, 200, and 300 MW) when the PHS plant is charged. This limitation is included to capture the fact that current technologies being evaluated by investors in Chile do not present drives with variable speed. Indeed, upgrading the drive to feature variable speed, as studied in [39], can increase the benefits

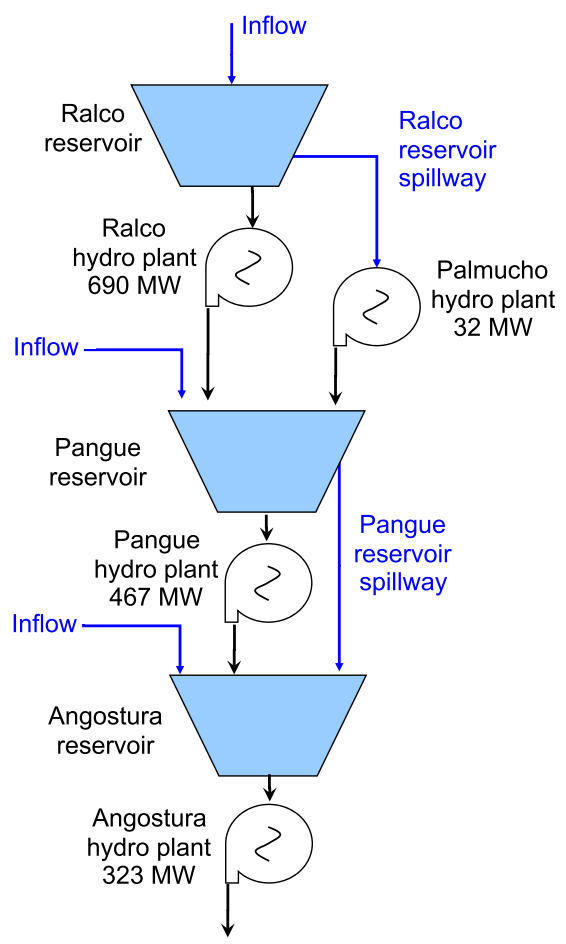

Fig. 2 Connection of hydropower plants throughout the Biobío river basin 


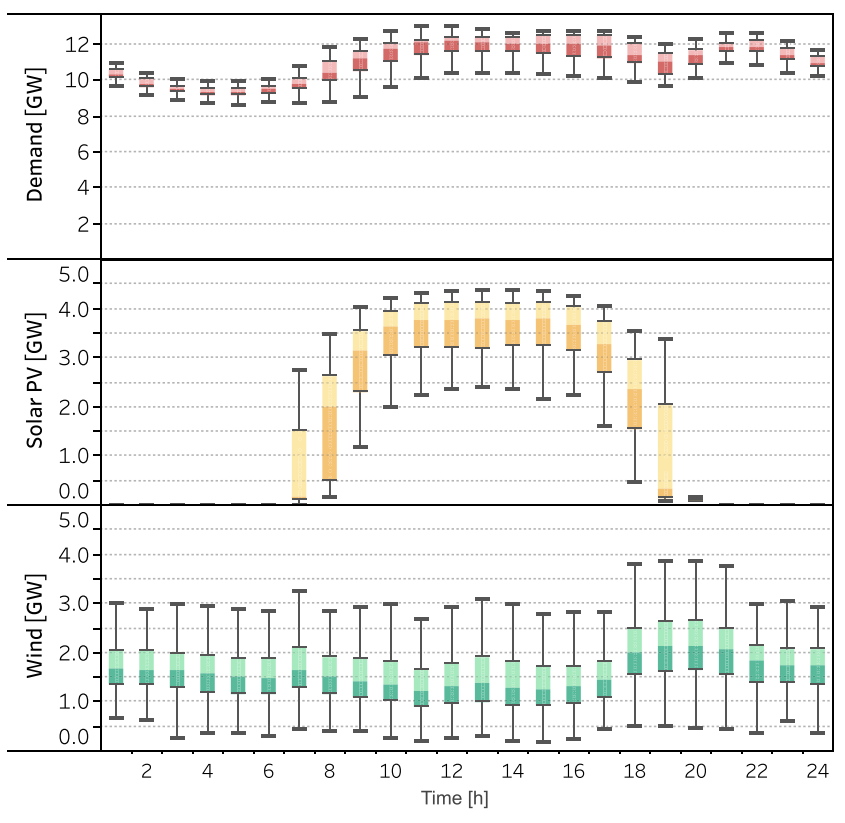

Fig. 3 Boxplot of hourly demand, solar PV, and wind generation in a day (yearly deviations)

of PHS. This PHS plant is located in the north, particularly in node 1 , where the installed capacity of solar power is the highest. Importantly, although Chile presents a high share of hydropower plants (that can potentially compete against PHS for the provision of flexibility and security), they are located in the southern part of the system, opposite to the location of solar resources. Hence, a PHS plant located in the north could present potentially higher benefits since Chile presents a long transmission network prone to bottlenecks.

\section{Studies}

We run the AM and SM with and without the PHS plant under two future scenarios in 2025 . The main objective is to compare the benefits of the PHS plant estimated by the SM, against those obtained by running the AM, quantifying the

Table 3 Main parameters of the Chilean system in 2025

\begin{tabular}{ll}
\hline Characteristic & Value \\
\hline Peak electricity demand $(\mathrm{GW})$ & 12.95 \\
Yearly electricity demand $(\mathrm{TWh})$ & 96 \\
Coal price range $(\$ /$ ton$)$ & $70-90$ \\
LNG price range $(\$ / \mathrm{MBTU})$ & $8-11$ \\
Diesel price range $\left(\$ / \mathrm{m}^{3}\right)$ & $600-800$ \\
Primary reserve requirement $(\mathrm{MW})$ & 327 \\
Secondary reserve requirement $(\mathrm{MW})$ & 120 \\
Tertiary reserve requirement $(\mathrm{MW})$ & $143-316$ \\
\hline
\end{tabular}

size of the numerical errors originated by the simplifying assumptions traditionally used in energy system planning studies. The benefits studied include operational costs savings, investment costs savings (in both transmission network capacity and peaking units), $\mathrm{CO}_{2}$ emissions reductions, and renewables curtailments reductions. We also study and conclude, through the advanced model, on the real value of a PHS plant in Chile.

Finally, we also analyze the benefits associated with a PHS plant from a private perspective, by using the dual variables of the optimization models as energy and reserves market prices. Here, we assess the private benefits (i.e., revenues) under the same two future scenarios and determine the numerical errors of simplifying assumptions.

\section{Numerical Results}

\section{General Results}

In this section, we quantify the impacts of adding a 300MW PHS plant on two future scenarios of the Chilean electricity system in 2025, introduced in the previous section. These impacts are measured in terms of operational costs (OPEX) savings, investment costs (CAPEX) savings, $\mathrm{CO}_{2}$ emissions reductions, and renewables curtailments reductions as explained next.

1. OPEX savings are originated by the ability of PHS to perform energy arbitrage (buying energy during low-price hours and selling it during high-price hours), provide reserve services and provide flexibility, supporting a more cost-effective operation of the power system when facing technical constraints, even beyond reserve requirements, such as ramp rate limits, and minimum up- and downtimes. Flexibility also supports reduction of startup and shutdown costs of thermal power plants.

2. CAPEX savings are divided into two categories: generation and transmission. The one associated with generation is due to displacing or differing capacity of peaking plants since PHS can undertake peak shaving actions in a very cost-effective and reliable fashion. Savings in network infrastructure, on the other hand, can also be capitalized if the operation of the PHS plant leads to a reduction in the maximum power transfers and, in turn, in network capacity.

3. $\mathrm{CO}_{2}$ emissions reductions could be observed due to the ability of PHS to be charged at the time when renewable generation is available and discharge in hours when peaking and other thermal units operate. Importantly, PHS supports maximization of renewables output in an hour-by-hour fashion through flexibility contribution, 
and minimizing wind and solar power curtailments, which, in turn, reduces $\mathrm{CO}_{2}$ emissions.

4. Reductions in renewables curtailments may be observed when PHS capacity is integrated in power systems because storage plants, fundamentally, provide further means to optimize operation. In this vein, being renewables zero marginal cost generation, energy storage may maximize their outputs with the aim of minimizing operational costs.

The abovementioned benefits are quantified and shown in Table 4. These results are displayed for two future scenarios and by using two models: one with a detailed time resolution (AM) and one with a poorer time resolution (SM). The latter also neglects technical constraints (i.e., unit commitment constraints) of conventional generation as well as their startup and shutdown costs.

Expectedly, these results demonstrate that benefits of PHS capacity are higher under scenario 2, which presents increased capacity of solar power generation as shown in Table 2. In fact, this is the case for almost all benefits studied (i.e., all benefits calculated with the AM, except for GCAPEX, are higher under scenario 2). Savings in peaking plant capacity (i.e., G-CAPEX), though, remain the same under both scenarios.

Table 4 also shows that approximations in modeling that are very common in our field can lead to a significant underestimation when assessing the benefits of PHS, irrespective of the volumes of renewable generation capacity installed. In our studies, for example, the stylized model undervalues the benefits of PHS in both scenarios. Furthermore, we observe an important distortion in the emission results of the stylized model. Indeed, this reports an increase in the volumes of $\mathrm{CO}_{2}$ emissions when PHS capacity is integrated. Note this is conflicting with the right set of results, calculated through the more precise model (AM), which demonstrates that $\mathrm{CO}_{2}$ emissions are effectively reduced with the integration of PHS capacity.
Importantly, the above problems due to modeling approximations are of upmost relevance for policy-makers, who are attempting to calculate the right value of PHS capacity in future scenarios. Next, we analyze in more detail the previous results and problems found.

\section{Operational Cost Savings (OPEX)}

Table 4 demonstrates that a detailed representation of system operation is paramount for the correct assessment of the benefits of PHS capacity. This is so since provision of services related to energy arbitrage, reserves, and flexibility is better captured in models with higher time resolution and appropriate representation of all constraints and costs associated with conventional generation (i.e., unit commitment constraints such as ramp rate limits, minimum stable outputs, minimum up- and downtimes, and representation of startup and shutdown costs).

In this vein, Fig. 4 shows the system and PHS operation determined under the two models in scenario 1 for a particular workday of year 2025. While hour-byhour variability of renewables and technical constraints is appropriately considered by the AM approach, the operation of the SM approach seems clearly discretized, undermining the need to operate more expensive power units, whose outputs are minimized as illustrated in Fig. 4b.

Furthermore, Fig. 4 shows three noticeable differences between the results of SM and AM approaches. Firstly, outputs of coal generation are more flexible in the stylized model, being significantly reduced when solar generation produces power. This is so since this model can truly maximize the output of zero marginal cost generation without appropriately considering the technical constraints of both coal power units and other thermal units. Indeed, under the right, more accurate model, coal plants have limitations to deal with variable renewable generation due to slow changes in outputs and constraining minimum stable generation limits. Secondly, LNG and diesel units are
Table 4 Total OPEX, CAPEX, and $\mathrm{CO}_{2}$ emissions and wind-solar curtailments reductions due to installation of PHS plant in two future scenarios and under two modeling approaches (negative values refer to an increase)

\begin{tabular}{|c|c|c|c|c|}
\hline & \multicolumn{2}{|c|}{ Scenario 1} & \multicolumn{2}{|c|}{ Scenario 2} \\
\hline & $\mathrm{AM}$ & SM & $\mathrm{AM}$ & $\mathrm{SM}$ \\
\hline OPEX (M\$/year) & 33.8 & 4.6 & 46.5 & 16.6 \\
\hline G-CAPEX (M\$year) & 20.4 & 11.6 & 20.4 & 17.0 \\
\hline T-CAPEX (M\$year) & 15.4 & 5.7 & 20.9 & 11.6 \\
\hline Total (M\$/year) & 69.6 & 21.9 & 87.8 & 45.3 \\
\hline $\mathrm{CO} 2$ emissions ( $\mathrm{ktCO}_{2} /$ year $)$ & 200 & -393 & 880 & -20 \\
\hline Wind-solar curtailments (GWh/year) & 576 & 0 & 1270 & 377 \\
\hline
\end{tabular}

$M$ in $\mathrm{M} \$$ refers to million American dollars 


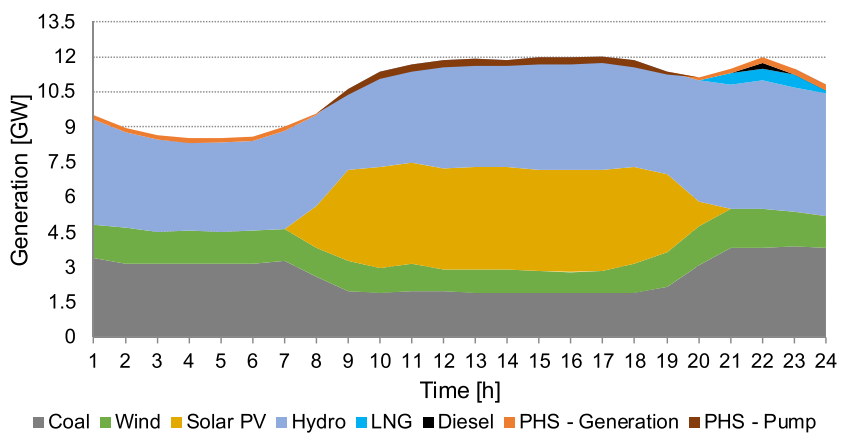

(a)

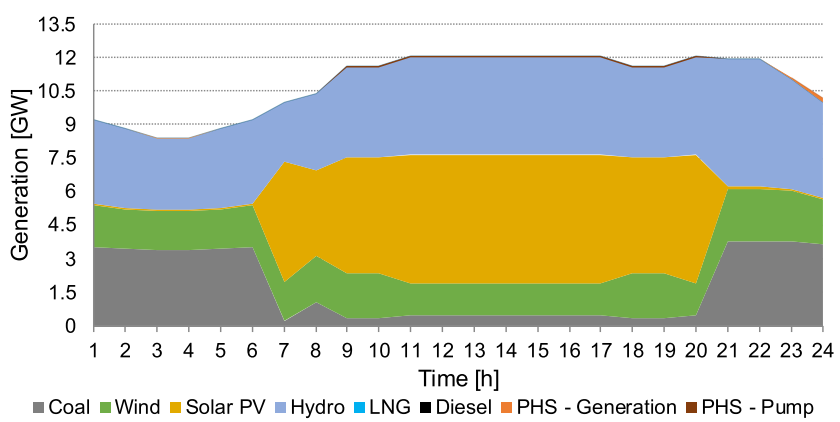

(b)

Fig. 4 Hourly operation determined by the a AM and b SM approaches

needed, especially to deal with peak demands, and this is undermined by the stylized model. Thirdly, the PHS plant is dispatched more actively under the AM so as to provide peak shaving and other energy, security, and flexibility services.

Interestingly, the simplifications in question not only leads to significant errors in the assessment of social costs and benefits, but also in the assessment of private benefits. To illustrate this point, Fig. 5 shows both the operation of PHS plant and the marginal cost (or spot price) in the node where this plant is located under the two modeling approaches (in scenario 1). Clearly, both PHS plant operation and energy prices significantly differ between the two modeling approaches, where SM leads to an important underestimation in revenues as shown in more detail in Table 5.

Table 5 shows the estimated savings in OPEX and the revenues of the PHS plant calculated under the two modeling approaches and in both scenarios. While the OPEX savings are directly obtained from Table 4, revenues are calculated as follows. In the case of energy arbitrage, hourly energy purchases and sells are multiplied by the spot price of energy in the node where the PHS plant is connected, which corresponds to the Lagrange multiplier (or dual/shadow price) of the energy balance constraint at that node. In the case of reserves services, hourly reserves amounts provided by the PHS plant are multiplied by the

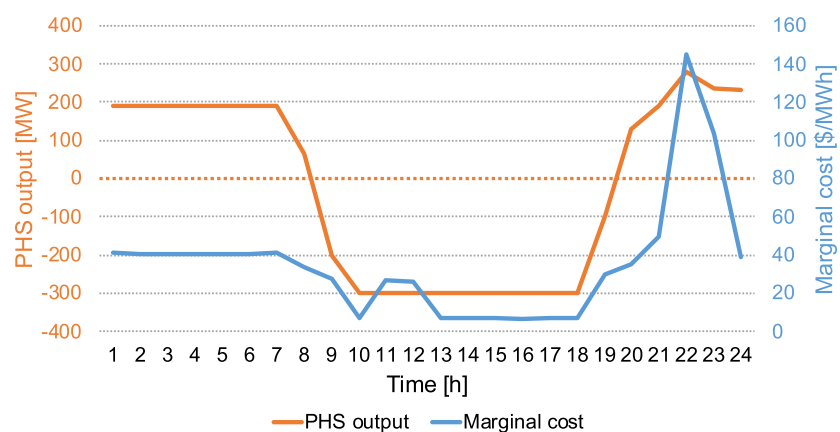

(a)

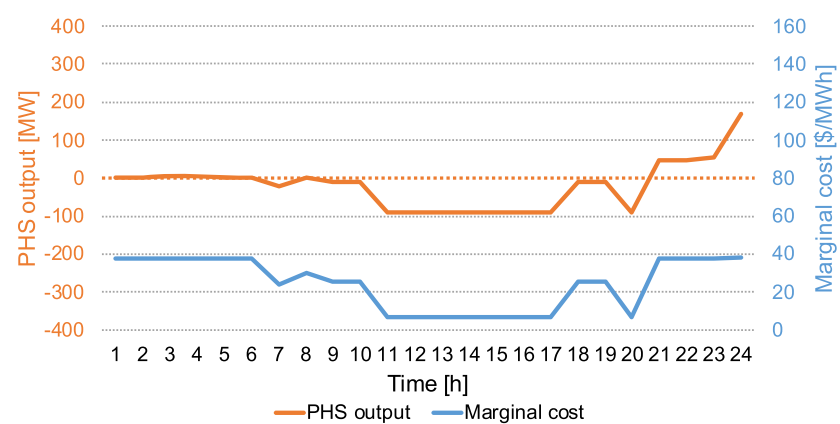

(b)

Fig. 5 PHS operation (in MW) and nodal marginal price (in \$/MWh) according to $\mathbf{a} \mathrm{AM}$ and $\mathbf{b}$ SM approaches. Negative power outputs refer to the charging operating mode of the storage plant

system prices of reserves, which are equal to the Lagrange multipliers of the constraints securing sufficient amounts of primary, secondary, and tertiary reserves [40]. As private revenues should be proportional to social benefits, the SM approach significantly undermines private revenues in both scenarios as well as social benefits. Remarkably, as shown by the results with the advanced model, energy arbitrage and reserves services are sufficient for the plant owner to capture an important proportion of the social benefits originated by installing the PHS plant.

\section{Investment Cost Savings in Peaking Plants}

As presented previously in Table 4, the savings obtained in terms of deferring peaking plant capacity (G-CAPEX) are

Table 5 OPEX savings and revenues of energy arbitrage and reserves services (in M\$/year)

\begin{tabular}{llllll}
\hline & \multicolumn{2}{l}{ Scenario 1} & & \multicolumn{2}{l}{ Scenario 2 } \\
\cline { 2 - 3 } \cline { 5 - 6 } & AM & SM & & AM & SM \\
\hline OPEX savings & 33.8 & 4.6 & & 46.5 & 16.6 \\
Total revenue (a) + (b) & 28.6 & 1.5 & & 44.4 & 11.9 \\
(a) Energy arbitrage & 24 & 1.5 & & 39.3 & 11.9 \\
(b) Reserves services & 4.6 & 0 & & 5.1 & 0 \\
\hline
\end{tabular}


the second largest reported in this analysis. Such savings are justified due to the role played by PHS capacity in peak shaving, which reduces the need for peaking plants. As in OPEX savings, here modeling simplifications (i.e., a stylized operation of the power system) can also lead to an important underestimation of the benefits in terms of CAPEX in generation capacity. In this context, Table 6 presents the amount of peaking plant capacity displaced in each scenario. In particular, in scenario 1, the capacity credit of PHS is undermined by $57 \%$ by the SM approach, reducing the capacity contribution of the PHS plant to less than half of the correct value determined by the AM approach.

This result may present profound implications in capacity recognition by regulators for remuneration purposes. Chile, for instance, features a cost-based economic dispatch, in which energy prices can only recover part of the overall costs of power plants since bids, that are audited, can reflect only variable costs of generation, ignoring opportunity costs [41]. So, there are administrative capacity payments paid to power plant owners so as to recover the total cost of operation and investment. In theory, capacity payments (plus energy market revenues) lead to full cost recovery only if investments are cost-effective and hence there is no excess of generation capacity in the market. Under these market arrangements, nameplate capacities are penalized in order to remunerate only the "firm" or "adequate" capacity of power plants. In this vein, our analysis suggests that the calculation of adequate or firm capacity (the capacity of peaking plant units that can be securely displaced or decommissioned due to the installation of PHS plant) can significantly differ from the right result if the model is too approximated. Clearly, administrative rules to calculate capacity payments should appropriately recognize the contribution of PHS to adequacy so as to align social benefits and economic incentives to investors.

\section{Investment Cost Savings in Transmission Capacity}

As shown in Fig. 1, the PHS plant in question that is located north of the country (node 1) is next to the Atacama desert and within a prominent area in Chile for the development of solar power generation. As the load center is located in Santiago (nodes 8-10), in the middle of the electricity system and about $1700 \mathrm{~km}$ from Atacama,

Table 6 Displaced peaking plant capacity by a 300-MW PHS unit in two scenarios and according to two models (in MW)

\begin{tabular}{llll}
\hline Scenario 1 & & Scenario 2 & \\
AM & SM & AM & SM \\
\hline 296 & 168 & 296 & 247 \\
\hline
\end{tabular}

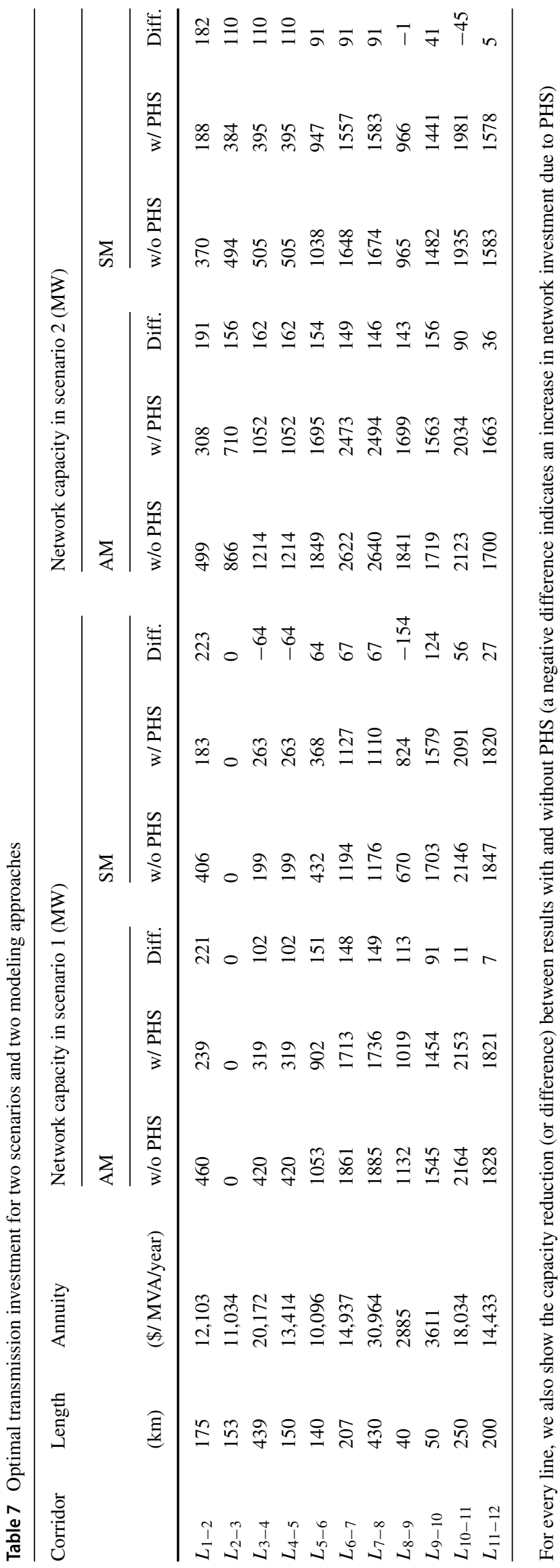


the model, under both scenarios, needs to build significant transmission infrastructure in order to transfer the solar power produced by new plants from the north to the center. This is shown in Table 7, where investments in new capacity for all transmission corridors modeled are shown for both scenarios, the two modeling approaches, and in the cases with and without the PHS plant.

Expectedly, as solar generation needs to be exported from the north at around noon, our AM demonstrates that the installation of the PHS plant can create important benefits in terms of displacing network capacity in the north-center transmission corridor, since the storage plant can be conveniently charged at the time of the maximum production from solar power generation, alleviating network congestions. A less expected result, though, is represented by the small savings in network investment costs south of the country, in the south-center corridor (e.g., $L_{11-12}$ ). Through various sensitivity analyses, we demonstrate that such savings exist because the PHS plant supplies part of the peak demand in Santiago during the evening, displacing the need to import power from the south during these hours. Interestingly, while maximum transfers in the northcenter corridor occur at around noon (due to solar power generation), the time of the maximum transfers in the southcenter corridor coincides with Santiago's maximum demand time in the evening. Hence, the installation of the PHS plant in the north can support transfer minimization in both northern and southern lines as charge and discharge actions occur at convenient times to alleviate network congestions.

Regarding the numerical errors in the stylized model, as mentioned earlier, savings under the AM are larger than those determined by the SM, highlighting the importance of a refined time resolution in these studies. However, this is not the case in every individual corridor. For example, corridor $L_{5-6}$ in scenario 1 presents a reduction of 151 MW according to the AM, contrasting with the $64 \mathrm{MW}$ determined by the SM, which clearly undermines the benefits of PHS. But, corridor $L_{9-10}$ in scenario 1, instead, presents a reduction of only $91 \mathrm{MW}$ according to the AM, contrasting with the $124 \mathrm{MW}$ determined by the SM. In this case, the SM overestimates the benefits of PHS. In our studies, SM tends to underestimate the benefits of PHS plant in terms of the total network investment costs, but, as demonstrated above, this may not be the case for every individual transmission project.

\section{Reductions in $\mathrm{CO}_{2}$ Emissions and Renewables Curtailments}

As discussed earlier, under the advanced modeling approach, PHS reduces $\mathrm{CO}_{2}$ emissions in both scenarios as shown in Table 8. How these reductions are justified, though, is not straightforward. Our AM demonstrates that, in scenario 1, the operation of PHS increases coal generation by $150 \mathrm{GWh} /$ year, while, in scenario 2, the integration of the PHS plant decreases production from coal-fired plants by $512 \mathrm{GWh} /$ year. Indeed, coal generation can be increased by energy storage systems as indicated in [42] since these systems provide further means for system operators to reduce costs by facilitating higher outputs of low-cost power plants, including, sometimes, coal power units. Also, in both scenarios, more than $500 \mathrm{GWh}$ /year from LNG plants is displaced by renewables since the operation of the PHS plant reduces wind and solar power spills. In fact, the increased dispatches of solar and wind power plants due to PHS lead to lower $\mathrm{CO}_{2}$ emissions too.

Remarkably, a model with lower resolution in operational timescales (SM) may lead to significantly large errors in the calculation of $\mathrm{CO}_{2}$ emission reductions due to PHS operation. In fact, while the AM determines a saving of $200,000 \mathrm{tCO}_{2} /$ year in scenario 1 , the SM calculates an increase of 393,000 $\mathrm{tCO}_{2} /$ year. Table 2 suggests that this large error is mainly due to two reasons. First, benefits of PHS in terms of reducing renewables curtailments can be significantly underestimated by a model that cannot capture extreme conditions that may happen in the hour-by-hour operation of the system like combinations of low demand conditions with high renewables outputs. Capturing extreme

Table 8 Reductions in generation by technology and in $\mathrm{CO}_{2}$ emissions at a system level (negative values indicate increases) when including a PHS plant in the two scenarios and two modeling approaches

\begin{tabular}{lllll}
\hline & \multicolumn{2}{l}{ Scenario 1} & & \multicolumn{2}{c}{ Scenario 2 } \\
\cline { 2 - 5 } & AM & SM & AM & SM \\
\hline Coal (GWh/year) & -150 & -507 & 512 & -213 \\
LNG (GWh/year) & 585 & 369 & 510 & 0 \\
Diesel (GWh/year) & 9.0 & 0 & 9.2 & -201 \\
Solar (GWh/year) & -166 & 0 & -1201 & -140 \\
Wind (GWh/year) & -411 & 0 & -69 & -20 \\
$\mathrm{CO}_{2}$ emissions (ktCO $/$ year) & 200 & -393 & & 880 \\
\hline
\end{tabular}


conditions is key since, under such conditions, renewables may be curtailed. Second, the impacts of PHS on the operation of coal and LNG plants can also be importantly miscalculated. For example, in scenario 2, while coal power outputs are reduced due to PHS operation according to AM, the SM approach suggests an increase in coal power outputs. This highlights the importance of appropriate modeling to truly capture the increases and decreases in the dispatch of different generation technologies and hence the final trend of $\mathrm{CO}_{2}$ emissions when integrating PHS capacity.

The miscalculation of $\mathrm{CO}_{2}$ emission reductions by the SM can present important policy implications. In Chile, investments in storage plants can be materialized under two approaches: a market-driven and a regulated/mandated one. Under the market-driven approach, investors are supposed to stack revenues from several markets, providing energy and a series of ancillary services and thus recovering their investment costs. Under the regulated approach, instead, investors are supposed to be remunerated through regulated payments and the investments should be proved necessary through a regulated cost-benefit analysis. As the regulated cost-benefit analysis is a study similar to that presented above, there is a significant risk of undermining the value of PHS in the regulated planning process if models used by regulators are similar to our SM. Interestingly, under the market-driven approach, benefits of $\mathrm{CO}_{2}$ emissions reductions associated with storage can also be misplaced. In fact, Chile presents a cost-based electricity market, in which the economic dispatch problem solved by the system operator only captures audited variable costs of power plants. Furthermore, generators are forbidden to include carbon taxes paid by them in their audited variable costs as explained in [43]. Consequently, spot prices do not reflect the extra marginal costs due to $\mathrm{CO}_{2}$ emissions, potentially undermining the incentives for investors to install energy storage.

\section{Conclusions}

We estimate the value of incremental energy storage capacity in the Chilean electricity market by using two mathematical models with different levels of simplification. The key distinction between these two models is the treatment of operational details within the planning process. Hence, in the most simplified model (called the stylized model in this paper), we ignore unit commitment constraints and the hourly variability of various datasets by using an array of time slices to represent different system conditions. We undertake our assessments under two future scenarios in 2025 , both representing fast growing of renewables such as wind and solar power generation.

We found that simplifications commonly used by regulators within long-term energy planning studies significantly underestimate the value of incremental PHS capacity. Indeed, we found that the value of the PHS plant obtained by using simplifications is less than a third $(31 \%)$ than that determined by the more advanced model in one of the scenarios. Remarkably, this is not the largest error. In terms of $\mathrm{CO}_{2}$ emissions, for instance, our studies demonstrate that simplifications can drive an increase in $\mathrm{CO}_{2}$ emissions due to an increment in PHS capacity, while the correct solution obtained by the advanced model clearly shows that $\mathrm{CO}_{2}$ emissions decrease. From a private perspective, we also found significant differences in terms of revenues for plant owners. Indeed, in one of the scenarios, the revenues due to energy arbitrage by the stylized model were only a small fraction $(6 \%)$ of that determined by the advanced model.

These results suggest that the value of PHS capacity significantly depends on the operational resolution used in long-term energy planning studies by policy-makers, regulators, planners, and investors. This is particularly important in light of, for example, setting policy incentives for energy storage technologies or determining mandated energy storage investments, which is one of the approaches adopted in Chile. This also expands to PHS developers, in a market-driven environment, who can significantly undermine the revenues of energy storage if the planning tool used is too stylized.

Funding The research in this article was supported by the Complex Engineering Systems Institute (ANID PIA/APOYO AFB180003), ANID FONDECYT \#1181928, FONDECYT \#1190228, ANID/FONDAP/ 15110019 (SERC-CHILE), ANID-Basal Project FB0008, and ANID/ PIA/ACT192094.

Open Access This article is licensed under a Creative Commons Attribution 4.0 International License, which permits use, sharing, adaptation, distribution and reproduction in any medium or format, as long as you give appropriate credit to the original author(s) and the source, provide a link to the Creative Commons licence, and indicate if changes were made. The images or other third party material in this article are included in the article's Creative Commons licence, unless indicated otherwise in a credit line to the material. If material is not included in the article's Creative Commons licence and your intended use is not permitted by statutory regulation or exceeds the permitted use, you will need to obtain permission directly from the copyright holder. To view a copy of this licence, visit http:// creativecommonshorg/licenses/by/4.0/.

\section{References}

1. International Renewable Energy Agency (IRENA), Renewable power generation costs in 2018, https://www.irena. org/publications/2019/May/Renewable-power-generationcosts-in-2018 (may 2019).

2. REN21, Renewables 2019 global status report, https://www. ren21.net/wp-content/uploads/2019/05/gsr_2019_full_report_en. pdf. 2019.

3. Strbac G, Aunedi M, Konstantelos I, Moreira R, Teng F, Moreno R, Pudjianto D, Laguna A, Papadopoulos P. Opportunities for energy storage: Assessing whole-system 
economic benefits of energy storage in future electricity systems. IEEE Power Energy Mag. 2017;15(5):32-41.

4. Moreno R, Moreira R, Strbac G. A milp model for optimising multi-service portfolios of distributed energy storage. Appl Energy. 2015;137:554-566.

5. Strbac G, Aunedi M, Pudjianto D, et al. Strategic assessment of the role and value of energy storage systems in the UK low carbon energy future. Technical report. 2012.

6. Suazo-Martínez C, Pereira-Bonvallet E, Palma-Behnke R. A simulation framework for optimal energy storage sizing. Energies. 2014;7(5):3033-3055.

7. Go RS, Munoz FD, Watson J-P. Assessing the economic value of co-optimized grid-scale energy storage investments in supporting high renewable portfolio standards. Appl Energy. 2016;183:902913.

8. Sioshansi R, Madaeni SH, Denholm P. A dynamic programming approach to estimate the capacity value of energy storage. IEEE Trans Power Syst. 2014;29(1):395-403.

9. Zhou Y, Mancarella P, Mutale J. Framework for capacity credit assessment of electrical energy storage and demand response. IET Gener Transm Distrib. 2016;10(9):2267-2276.

10. Konstantelos I, Strbac G. Valuation of flexible transmission investment options under uncertainty. IEEE Trans Power Syst. 2015;30(2):1047-1055.

11. Moreno R, Street A, Arroyo JM, Mancarella P. Planning low-carbon electricity systems under uncertainty considering operational flexibility and smart grid technologies, Philosophical Transactions of the Royal Society of London A: Mathematical, Physical and Engineering Sciences 375 (2100), The authors present a framework suitable of assessing the value of several flexible smart grid technologies over conventional solutions, leading to a more efficient planning solution.

12. Denholm P, Mai T. Timescales of energy storage needed for reducing renewable energy curtailment. Renew Energy. 2019;130:388-399.

13. de Sisternes FJ, Jenkins JD, Botterud A. The value of energy storage in decarbonizing the electricity sector. Appl Energy. 2016;175:368-379.

14. van Stiphout A, Brijs T, Belmans R, Deconinck G. Quantifying the importance of power system operation constraints in power system planning models: a case study for electricity storage. J Energy Stor. 2017;13:344-358. The authors show the importance of operational detail in long-term planning models in order to accurately assess the value of short-term flexible assets like energy storage technologies.

15. Thangavelu SR, Khambadkone AM, Karimi IA. Long-term optimal energy mix planning towards high energy security and low GHG emission. Appl Energy. 2015;154:959-969.

16. Cole W, Frew B, Mai T, Sun Y, Bistline J, Blanford G, Young D, Marcy C, Namovicz C, Edelman R, et al. Variable renewable energy in long-term planning models: a multi-model perspective. Pittsburgh: Tech. rep., National Energy Technology Lab.(NETL); 2017.

17. Loulou R, Goldstein G, Kanudia A, Lehtila A, Remne U. Documentation for the times model-part 1. 2016.

18. Loulou R, Goldstein G, Kanudia A, Lehtila A, Remne U. Documentation for the times model-part 2. 2016.

19. Ministerio de Energía de Chile, Planificación energética de largo plazo 2018, http://pelp.minenergia.cl/.

20. Comisión Nacional de Energía (CNE), Informe técnico preliminar plan de expansión anual de la transmisión, https://www.cne.cl/ tarificacion/electrica/expansion-de-transmision/. 2019.

21. Poncelet K, Delarue E, Six D, Duerinck J, D'haeseleer W. Impact of the level of temporal and operational detail in energysystem planning models. Appl Energy. 2016;162:631-643. This work demonstrates that temporal representation simplifications in long-term planning models should be significantly improved in systems with a large share of variable renewable energy.

22. Pina A, Silva C, Ferrão P. Modeling hourly electricity dynamics for policy making in long-term scenarios. Energy Policy. 2011;39(9):4692-4702.

23. Welsch M, Deane P, Howells M, Gallachóir BÓ, Rogan F, Bazilian M, Rogner H-H. Incorporating flexibility requirements into long-term energy system models-a case study on high levels of renewable electricity penetration in ireland. Appl Energy. 2014;135:600-615.

24. Brijs T, van Stiphout A, Siddiqui S, Belmans R. Evaluating the role of electricity storage by considering short-term operation in long-term planning. Sustain Energy Grids Netw. 2017;10:104117.

25. Shortt A, Kiviluoma J, O’Malley M. Accommodating variability in generation planning. IEEE Trans Power Syst. 2012;28(1):158169.

26. Diaz G, Inzunza A, Moreno R. The importance of time resolution, operational flexibility and risk aversion in quantifying the value of energy storage in long-term energy planning studies. Renew Sustain Energy Rev. 2019;112:797-812. This work compares different long-term planning modeling approaches, finding that total installed storage capacity escalates as modeling complexity increases.

27. Escobar RA, Cortés C, Pino A, Salgado M, Pereira EB, Martins FR, Boland J, Cardemil JM. Estimating the potential for solar energy utilization in Chile by satellite-derived data and ground station measurements. Sol Energy. 2015;121:139-151.

28. Comisión Nacional de Energía (CNE), Informe técnico preliminar plan de expansión anual de la transmisión, https://www.cne.cl/ tarificacion/electrica/expansion-de-transmision/. 2017.

29. Krishnan V, Ho J, Hobbs BF, Liu AL, McCalley JD, Shahidehpour M, Zheng QP. Co-optimization of electricity transmission and generation resources for planning and policy analysis: review of concepts and modeling approaches. Energy Syst. 2016;7(2):297-332.

30. You S, Hadley SW, Shankar M, Liu Y. Co-optimizing generation and transmission expansion with wind power in large-scale power grids. implementation in the US Eastern interconnection. Electr Power Syst Res. 2016;133:209-218.

31. Hobbs BF, Rothkopf MH, O'Neill RP, Chao H-p, Vol. 36. The next generation of electric power unit commitment models. London: Springer Science \& Business Media; 2006.

32. Carrión M, Arroyo JM. A computationally efficient mixed-integer linear formulation for the thermal unit commitment problem. IEEE Trans Power Syst. 2006;21(3):1371-1378.

33. Flores-Quiroz A, Palma-Behnke R, Zakeri G, Moreno R. A column generation approach for solving generation expansion planning problems with high renewable energy penetration. Electric Power Syst Res. 2016;136:232-241. The authors present a decomposition approach to overcome the computational burden associated with increased operational details in planning models.

34. Palmintier B, Webster M. Impact of unit commitment constraints on generation expansion planning with renewables. In: 2011 IEEE power and energy society general meeting. IEEE; 2011. p. 1-7.

35. Shahidehpour M, Fu Y. Benders decomposition in restructured power systems. IEEE Techtorial.

36. Inzunza A, Moreno R, Bernales A, Rudnick H. Cvar constrained planning of renewable generation with consideration of system inertial response, reserve services and demand participation. Energy Econ. 2016;59:104-117.

37. GIZ and Ministerio de Energía de Chile, Energías renovables en chile el potencial eólico, solar e hidroeléctrico de arica a chiloé, http://www.minenergia.cl/archivos_bajar/Estudios/ Potencial_ER_en_Chile_AC.pdf. 2014. 
38. Coordinador Eléctrico Nacional (CEN), Sistema de información pública, https://infotecnica.coordinador.cl/.

39. Teng F, Pudjianto D, Aunedi M, Strbac G. Assessment of future whole-system value of large-scale pumped storage plants in Europe. Energies. 2018;11(1):246.

40. Kirschen D, Strbac G. Fundamentals of power system economics. UK: Wiley; 2004.

41. Munoz FD, Wogrin S, Oren SS, Hobbs BF. Economic inefficiencies of cost-based electricity market designs. Energy J 39(3).
42. Ummels B, Pelgrum E, Kling W. Integration of large-scale wind power and use of energy storage in the Netherlands' electricity supply. IET Renew Power Gener. 2008;2(1):34-46.

43. Diaz G, Muñoz FD, Moreno R. Equilibrium analysis of a tax on carbon emissions with pass-through restrictions and side-payment rules. Energy J 41(2).

Publisher's Note Springer Nature remains neutral with regard to jurisdictional claims in published maps and institutional affiliations.

\section{Affiliations}

\section{Eduardo Pereira-Bonvallet $^{1} \cdot$ Rodrigo Moreno $^{2,3,4}$ (D) . Francisco D. Muñoz ${ }^{5}$}

\section{Eduardo Pereira-Bonvallet}

epereira@spec.cl

Francisco D. Muñoz

fdmunoz@uai.cl

1 SPEC Energy Consulting, Santiago, Chile

2 University of Chile, Santiago, Chile

3 Instituto Sistemas Complejos de Ingeniería, Santiago, Chile

4 Imperial College, London, UK

5 Universidad Adolfo Ibáñez, Santiago, Chile 